\title{
Avaliação da aprendizagem conceitual
}

\section{Evaluation of conceptual learning}

\author{
Vanize Aparecida Misael de Andrade Vieira ${ }^{1}$ \\ Marta Sueli de Faria Sforni ${ }^{2}$
}

\begin{abstract}
RESUMO
Este artigo apresenta resultados de uma pesquisa que teve como objetivo investigar concepções, práticas e perspectivas de avaliação da aprendizagem conceitual em contexto escolar. Mediante estudos bibliográficos e entrevistas, buscou-se analisar a avaliação em três âmbitos: nas produções teóricas contemporâneas, nos documentos educacionais e nas concepções e práticas avaliativas de professores das séries iniciais do ensino fundamental. Na análise dos dados identificou-se profunda semelhança entre as concepções de avaliação presentes nos três âmbitos investigados. Neles evidencia-se a preocupação em romper com uma prática de avaliação autoritária, seletiva e realizada ao fim do processo de ensino. Buscando-se a implementação de formas de avaliação mais democráticas e comprometidas com a aprendizagem do aluno, são propostas novas formas de avaliação, como a diagnóstica, contínua e formativa. Para que se possa avançar nessas propostas faz-se necessário aprofundar estudos na compreensão do próprio processo de aprendizagem conceitual. Com a intenção de encontrar subsídios teórico-metodológicos que possam embasar a ação docente na prática avaliativa, buscaram-se inferências em teorizações feitas por Vygotsky e Leontiev acerca da formação de conceitos, tendo em vista o conteúdo que deve ser externalizado pelo aluno como indicador de sua aprendizagem.
\end{abstract}

Palavras-chave: aprendizagem conceitual; avaliação escolar; Vygotsky; Leontiev.

\begin{abstract}
This article presents results from some research that aimed at investigating concepts, practices and perspectives of conceptual learning evaluation in a school context. The evaluation of three situations, or rather contempo-
\end{abstract}

1 Mestre em Educação pela Universidade Estadual de Maringá (UEM), Professora da Rede Estadual de Ensino do Paraná, Brasil. E-mail: vanizevieira@hotmail.com.

2 Doutora em Educação pela Universidade de São Paulo (USP) e Professora do Programa de Pós-Graduação em Educação da Universidade Estadual de Maringá (UEM), Brasil. E-mail: martasforni@uol.com.br. 
rary theoretical productions, education documents and evaluation concepts and practices of junior school teachers, was analyzed through bibliographical studies and interviews. Data analysis identified a deep similarity among evaluation concepts in the three contexts mentioned above in which a concern of going beyond an authoritarian and selective evaluation performed at the end of the teaching process predominates. New types of evaluation forms, such as a diagnostic, continuous and formative type, have been suggested to establish more democratic evaluations committed to the students' learning. Investigations on the understanding of the conceptual learning process are needed so that an improvement related to those suggestions could be undertaken. Inferences in theorizations by Vygotsky and Leontiev on concept formation have been undertaken for theoretical and methodological subsidies to foreground teacher activities in evaluation, keeping in mind the contents that should be externalized by the student as learning indicators.

Keywords: conceptual learning; school work evaluation; Vygotsky; Leontiev.

\section{Introdução}

Muito se tem discutido sobre a avaliação da aprendizagem. A realização de Seminários, Simpósios, grupos de estudos sobre o referido tema, envolvendo professores e equipe pedagógica comprova como é frequente essa discussão em contexto educacional. No entanto, identificamos que embora seja tema recorrente, muitas dúvidas ainda cercam sua prática.

Afinal, que contribuições para a prática avaliativa ofereceram os estudos acadêmicos e os documentos oficiais sobre esse tema? Como os professores têm realizado a avaliação da aprendizagem dos alunos? Como é possível avançar em princípios teóricos e metodológicos nesse campo?

Para compreendermos como a avaliação da aprendizagem é tratada na atualidade, analisamos como tem sido abordado o tema nos documentos oficiais, nas produções teóricas contemporâneas e na prática educacional. Posteriormente, buscamos subsídios teóricos nas produções de Vygotsky e Leontiev acerca da formação de conceitos, procurando compreender a especificidade desse tipo de aprendizagem, para depreender desse referencial princípios orientadores para a avaliação da aprendizagem conceitual. 


\section{As críticas ao modelo tradicional e as novas propostas de avaliação da aprendizagem}

Com o processo de abertura política e democratização da sociedade brasileira, intensificado a partir de 1980, o modelo autoritário e excludente de escola, expresso na organização do ensino, incluindo currículo, metodologia e planejamento, é severamente criticado. Obviamente, nesse contexto, a avaliação escolar passa a ser amplamente discutida e é considerada como uma prática autoritária e seletiva (LUCKESI, 1998; PERRENOUD, 1999; SAUL, 1988; SOUSA, 1995; HOFFMAN, 1993, 1995). Ao adotar esse modelo de avaliação, considera-se que a escola reforça um modelo de sociedade repressivo e discriminatório nos aspectos social, econômico e cultural. As palavras de Sousa representam bem esse contexto de críticas. Para ela:

[...] como parte de uma ação política que visa a discriminar, através do processo educativo, aqueles que a sociedade já mantém discriminados sócio-econômica e culturalmente. A crença liberal no esforço e no mérito pessoal como responsáveis pelo sucesso do aluno em um processo educativo tem utilizado a avaliação como um instrumento de legitimação da seletividade da educação e conferido ao ensino e às escolas um papel subsidiário diante do fracasso escolar (SOUSA, 1995, p. 146).

Denuncia-se que a prática avaliativa conduzida dessa maneira, além de servir ao professor como um mecanismo disciplinador, prioriza apenas a classificação e não tem propósitos pedagógicos, pois nenhuma decisão é tomada no sentido de ensinar aos alunos o que ainda não aprenderam.

De acordo com Luckesi (1998), uma avaliação escolar conduzida de forma inadequada pode, consequentemente, ocasionar a repetência do aluno, ou mesmo causar sua evasão. Como deveria ser então, para esses autores, uma prática avaliativa democrática e articulada com o processo de ensino e aprendizagem?

Hoffmann (1995, p. 21) defende que: “A avaliação deixe de ser o momento terminal do processo educativo [...] para se transformar na busca incessante de compreensão das dificuldades do educando e na dinamização de novas opor- 
tunidades de conhecimento". Para isso, ela deve ser contínua, realizada em diferentes momentos, oportunizando um acompanhamento sistematizado da aprendizagem do aluno pelo professor. Assim surgem propostas de avaliação diagnóstica, formativa, contínua, dentre outras.

Essas propostas da prática avaliativa foram muito difundidas nos cursos de formação inicial e continuada de professores. Inclusive, os pressupostos dessas propostas estão presentes na Lei de Diretrizes e Bases da Educação Nacional 9394/96, sendo que o artigo 24 estabelece que a avaliação do desempenho do aluno deve ser contínua e cumulativa, prevalecendo os aspectos qualitativos sobre os quantitativos e os resultados ao longo do período sobre os de eventuais provas finais.

Também encontra-se nos Parâmetros Curriculares Nacionais (PCNs) a oposição à avaliação chamada tradicional, centrada em notas e conceitos, e a defesa de uma avaliação contínua da aprendizagem cujos resultados obtidos possibilitarão ao professor fazer uma reflexão sobre a sua prática e efetuar os ajustes adequados para que ocorra a aprendizagem dos alunos.

A avaliação subsidia o professor com elementos para uma reflexão contínua sobre a sua prática, sobre a criação de novos instrumentos de trabalho e a retomada de aspectos que devem ser revistos, ajustados ou reconhecidos como adequados para o processo de aprendizagem individual ou de todo o grupo (BRASIL, 1997, p. 81).

É possível identificar uma grande sintonia na produção teórica sobre a avaliação e nos documentos oficiais, o que nos leva a reconhecer que há unanimidade na crítica aos modelos de avaliação considerados tradicionais e a defesa de avaliações diagnósticas, processuais ou formativas.

Qual foi o impacto dessas discussões na prática pedagógica?

\section{As práticas avaliativas no ensino fundamental}

Para verificar em que medida as discussões teóricas e as orientações governamentais sobre a avaliação influenciaram a prática pedagógica analisamos: a) a fala de professores, coletada mediante entrevistas; b) a prática 
avaliativa na organização da escolaridade em ciclos e com aprovação automática e; c) a avaliação nos projetos considerados inovadores para o ensino fundamental.

As entrevistas semiestruturadas foram realizadas com 12 professoras da $4^{\mathrm{a}}$ série do ensino fundamental, de sete escolas de um município do Paraná, adotando como critério a localização da escola em diferentes bairros da cidade. Das escolas selecionadas, três são da rede estadual, duas da rede municipal e duas da rede particular. Centralizamos as perguntas em uma área de conhecimento específica - Ciências - para que em suas respostas, as professoras pudessem apresentar exemplos de como avaliam determinado conteúdo, oferecendo, dessa forma, dados mais objetivos para a nossa pesquisa.

Em suas falas os professores revelam com clareza quais os procedimentos ideais para uma prática avaliativa democrática: "é necessário avaliar tudo que o aluno faz", " a avaliação só tem sentido quando o que não foi aprendido é retomado", " a avaliação não pode limitar-se aos aspectos quantitativos", "a avaliação não deve ocorrer somente como provas no final do ano".

As entrevistas revelaram que embora as professoras não se refiram aos teóricos citados acima, suas falas expressam as concepções desses autores. Para elas, avalia-se para retomar, com o aluno, o conteúdo que não foi aprendido; no entanto, elas não utilizaram o termo "avaliação diagnóstica" para se referir a esse processo.

Observa-se que tanto as críticas como as formas de superação foram ouvidas por todas as professoras entrevistadas, tanto as que atuam na rede pública como as da escola particular.

Questionadas sobre quais atividades utilizavam para verificar se tinha havido a aprendizagem desejada, as professoras descreveram que consideravam importante utilizar atividades no caderno, produção de textos, cruzadinhas, diagramas, ilustrações, questões que envolvessem perguntas e respostas, descrição dos conteúdos trabalhados, exercícios de múltipla escolha, pesquisas e experiências.

Um aspecto importante revelado nas entrevistas é a preocupação das professoras em evitar as questões cujas respostas exigissem apenas a memorização mecânica dos conteúdos trabalhados. $\mathrm{O}$ interesse e a participação nas atividades propostas são considerados um "termômetro" da aprendizagem dos conteúdos trabalhados. No entanto, as professoras não estavam satisfeitas com essa forma de avaliação da aprendizagem, pois quando se lhes perguntou se as atividades utilizadas eram suficientes para verificar se houve ou não aprendizagens, apenas duas afirmaram que sim.

Embora não estivessem satisfeitas com a avaliação realizada, elas não conseguiam dizer o que faltava e quando questionadas sobre como o aluno 
expressa que aprendeu um conteúdo escolar, demonstram imprecisão em afirmar o que seria objetivamente demonstração de apropriação de conteúdos. Algumas professoras responderam que o aluno aprendeu um conteúdo quando mudou de comportamento. Outras professoras consideram que o aluno aprendeu o conteúdo quando participou da aula, questionou ou buscou informações em outras fontes diferentes da escola.

Consideramos que somente com esses elementos torna-se difícil avaliar a aprendizagem dos conteúdos. A participação e o interesse pelo conteúdo estudado não podem ser os únicos critérios para verificar se houve ou não aprendizagem, pois nesse percurso há inúmeros fatores que podem camuflar os resultados. Interesse é importante para o processo de apropriação de conhecimentos, mas não é sinônimo de aprendizagem.

Mediante as entrevistas foi possível observar que os professores têm dificuldades em definir parâmetros para a avaliação dos conteúdos específicos e insistem em fazer afirmações genéricas e superficiais sobre a avaliação, tais como: deve ser democrática; não deve ter por finalidade unicamente a emissão de notas; deve ser um instrumento para acompanhar a aprendizagem dos alunos. No entanto, os professores não conseguem dizer exatamente o que seria considerado como manifestação da aprendizagem dos conteúdos ensinados.

Entretanto, cabe lembrar que as discussões acadêmicas sobre o tema também não foram muito além desse tipo de afirmação. Ou seja, verifica-se uma sintonia entre as discussões teóricas sobre a avaliação e a prática desenvolvida em sala de aula. Essa sintonia, no entanto, sinaliza a necessidade de avançar nas discussões sobre a forma de avaliar (contínua, diagnóstica, formativa...) até agora realizadas e de nos direcionarmos para uma reflexão sobre o conteúdo da avaliação da aprendizagem.

Podemos inferir que as discussões referentes à avaliação da aprendizagem, tanto na formação acadêmica como nos cursos de formação continuada, ficaram restritas aos aspectos externos da didática, à forma, ao modo de avaliar. Assim, a preocupação maior voltou-se ao como avaliar em detrimento de o que avaliar.

\section{Em busca de subsídios na abordagem histórico-cultural}

\section{Contribuições de Vygotsky}

Pautado nos pressupostos do Materialismo Dialético, Vygotsky e seus colaboradores consideram o homem como sujeito ativo, e entendem que na 
atividade prática, nas interações que ele estabelece com o meio e com outros homens se desenvolvem suas funções psicológicas superiores (memória, atenção voluntária, imaginação, planejamento, abstração...).

Para Vygotsky, a relação entre ensino e desenvolvimento é tema central para a prática pedagógica, pois consiste no estudo de como a criança se apropria de novos conhecimentos sistematizados em conteúdos curriculares e como esses conhecimentos podem propiciar o desenvolvimento mental da criança, tendo-se em vista que a aprendizagem de conceitos é a fonte do desenvolvimento na idade escolar. Segundo o referido autor: "O pensamento em conceitos é uma nova forma de atividade intelectual, um modo novo de conduta, um novo mecanismo intelectual" (VYGOTSKY, 2001).

De acordo com as investigações realizadas por Vygotsky e seus colaboradores sobre o processo de formação de conceitos, chegou-se à conclusão de que todo conceito é um ato de generalização e envolve uma série de funções complexas do pensamento, como a atenção arbitrária, a memória lógica, a percepção e o raciocínio, bem como processos cognitivos como a abstração, a comparação e a discriminação. Por isso os conceitos não podem ser simplesmente memorizados e assimilados de forma mecânica.

Vygotsky faz uma distinção entre os conceitos aprendidos informalmente no cotidiano, que denomina de conceitos espontâneos, e os conceitos aprendidos formalmente na escola, adquiridos por meio do ensino sistematizado - os conceitos científicos.

Por conceitos espontâneos entendem-se os conceitos construídos na experiência pessoal e concreta das crianças, à medida que observam e manipulam os objetos que fazem parte de sua vivência.

Já os conceitos científicos não estão diretamente relacionados à observação e à ação imediata da criança, pois é necessário ir além da observação para conseguir sua apropriação. Esses conceitos são os conhecimentos sistematizados adquiridos por meio da instrução escolar.

Para a apropriação desse tipo de conceito é necessária uma intensa atividade mental por parte da criança, pois ele não é aprendido de forma mecânica, mas tão-somente com a transmissão de informações pelo professor:

[...] os conceitos científicos não são assimilados nem decorados pela criança, não são memorizados mas surgem e se constituem por meio de uma intensa tensão de toda a atividade do seu próprio pensamento (VYGOTSKY, 2001, p. 260). 
Nessa perspectiva, o domínio dos conceitos científicos não é resultado de meras associações e surge no processo de operação intelectual.

Para Vygotsky o conceito não é algo isolado, mas faz parte de um sistema. Fora do sistema, os conceitos estabelecem vínculos apenas com as palavras e com os próprios objetos, ou seja, vínculos empíricos (VYGOTSKY, 2001). Para o referido autor, a presença de um sistema próprio dos conceitos científicos diferencia qualitativamente o nível de pensamento exigido, relativamente aos conceitos espontâneos.

Embora conceitos espontâneos e conceitos científicos sejam diferentes em sua origem e desenvolvimento, eles estão intimamente inter-relacionados e exercem influência mútua.

O desenvolvimento dos conceitos científicos deve apoiar-se em um nível determinado de maturação dos conceitos espontâneos, pois o desenvolvimento desses conceitos, bem como a possibilidade de tomar consciência deles, só é possível quando os conceitos espontâneos da criança atingem um nível próprio.

Por sua vez, o conceito espontâneo modifica sua relação com o objeto na medida em que nele se insere o conceito científico, evidenciando a influência de um sobre o outro.

Podemos concluir, então, que o desenvolvimento dos conceitos espontâneos e o dos conceitos científicos estão inter-relacionados, embora eles percorram caminhos opostos: enquanto os conceitos espontâneos desenvolvem-se de forma ascendente para a generalização, os conceitos científicos desenvolvem-se de forma descendente. Sobre esses diferentes movimentos Vygotsky esclarece que o processo de desenvolvimento dos conceitos científicos

[...] nas condições de um sistema organizado, descende ao concreto, ao fenômeno, ao passo que a tendência do desenvolvimento dos conceitos espontâneos se verifica fora do sistema, ascendendo para as generalizações (VYGOTSKY, 2001, p. 244).

Com a apropriação de um conceito científico a criança vai além dos limites da sua experiência imediata, e com base no conhecimento abstrato consegue explicar o fenômeno que faz parte do seu dia a dia e por meio dessa abstração torna-se concreto, pensado, ou seja, ela desce do abstrato ao fenômeno propriamente dito. Já no desenvolvimento dos conceitos espontâneos o caminho é inverso, é ascendente. Isso significa que à medida que a criança apropria-se de um conceito e esse passa a ser vinculado a um sistema, ascende para as generalizações. 
Dos ensinamentos de Vygotsky é possível inferir que, se o conceito não é algo isolado e só existe em relação com outros conceitos, ele não pode ser avaliado fora do sistema do qual faz parte. Isso significa que é necessário verificar a apropriação de conceitos estabelecendo-se relações com outros conceitos. Dessa maneira, não basta definir algo, descrever suas características e funções, pois a definição ou a descrição verbal ou escrita não implicam apropriação.

Se as avaliações, mesmo que de diferentes formas, mantiverem-se presas à designação verbal do conceito, sem o estabelecimento de suas ralações com outros conceitos, e se essa generalização não descer ao concreto, sejam essas formas tradicionais ou inovadoras, não conseguem avaliar de fato se houve a apropriação conceitual.

\section{Contribuições de Leontiev}

Leontiev destaca na cultura os elementos que são promotores do desenvolvimento humano: os instrumentos físicos e os instrumentos simbólicos. $\mathrm{Na}$ obra "O desenvolvimento do psiquismo" ele procura mostrar a relação entre a atividade laborativa e o desenvolvimento do homem.

O homem, ao transformar a natureza, cria instrumentos com características humanas, isto é, diferentes daquelas naturalmente presentes nela. À medida que o homem modifica a natureza criando instrumentos para satisfazer a sua necessidade, ele apenas não passa de um tipo de objeto para outro: nesse objeto cultural está presente a ideia, o pensamento e ação dos homens.

Nesse processo, a atividade física e mental dos seres humanos "incorporase”, cristaliza-se no instrumento. Leontiev esclarece esse fenômeno:

O instrumento não é apenas um objecto de forma particular, de propriedades físicas determinadas; é também um objecto social, isto é, tendo um certo modo de emprego, elaborado socialmente no decurso do trabalho coletivo e atribuído a ele [...] Razão por que dispor de um instrumento não significa simplesmente possuílo, mas dominar o meio de acção de que ele é o objecto material de realização (LEONTIEV, 1978, p. 82).

Esse processo é denominado por Marx e, posteriormente, por Leontiev, de objetivação - processo no qual a atividade intelectual humana se transfere para os instrumentos físicos e para a linguagem, neles se objetivando. 
Na cultura material e não material produzida pela humanidade fica como que "em repouso" a atividade intelectual que lhe deu origem. Quando se apropria dessa cultura o sujeito faz sua a atividade intelectual que ali está objetivada. Esse processo é denominado de apropriação, e garante o desenvolvimento da sociedade humana, na medida em que cada geração já surge pautada na produção das gerações precedentes. Para Leontiev, a apropriação é um processo:

[...] que tem como conseqüência a reprodução no indivíduo de qualidades, capacidades e características humanas de comportamento. Em outras palavras, é um processo por meio do qual se produz na criança o que nos animais se consegue mediante a ação da hereditariedade; a transmissão para o indivíduo das conquistas do desenvolvimento da espécie (LEONTIEV, 2003, p. 65).

A criança, desde cedo, ao apropriar-se da linguagem e dos instrumentos físicos, apreende o que está disponível em sua cultura e dessa forma se humaniza. A linguagem tem um papel decisivo na organização e desenvolvimento dos processos de pensamento e carrega consigo os conceitos generalizados que constituem a fonte do conhecimento humano. Por isso, ao apropriar-se da linguagem, o homem apropria-se da experiência da humanidade construída ao longo do tempo.

Para Leontiev a apropriação é sempre um processo ativo, por meio dela são reproduzidas nos homens as capacidades desenvolvidas historicamente e é um processo mediatizado pelas relações entre os seres humanos.

Quais são as implicações dessa ideia quando pensamos em avaliação da aprendizagem? Como podemos avaliar se o aluno se apropriou ou não dos conceitos? Para responder a essas questões, utilizaremos as palavras de Leontiev:

Quando dizemos, por exemplo, que a criança "assimila" instrumentos, isto significa que começa a usá-los com precisão, que forma as correspondentes ações e operações motoras e mentais (LEONTIEV, 2003, p. 66).

Quando dizemos que uma criança "assimilou" algo, estamos literalmente afirmando que essa criança o "tomou como seu ou para si", apropriou-se do seu 
significado e incorporou esse conhecimento como instrumento do seu pensamento, quando o conceito passa a fazer parte das operações mentais da criança, ou seja, quando é incorporada como instrumento do seu pensamento.

O que se espera é que, quando o aluno se apropria dos conceitos, seu conhecimento se amplie e ele seja capaz de usá-los em situações diversas.

Leontiev nos faz ver que aprender um conceito não é apenas saber o seu conteúdo, mas também saber fazer uso dele como instrumento para pensar os objetos e fenômenos, reproduzindo, assim, "os traços essenciais da atividade acumulada" nele (LEONTIEV, 1978, p. 268).

Disto podemos inferir que verificar se o aluno está desenvolvendo ou desenvolveu a capacidade de utilizar o conceito como instrumento do pensamento deve ser objeto da atenção dos professores no momento da elaboração e acompanhamento da avaliação.

\section{Considerações finais}

Mediante a presente pesquisa verificamos que as concepções e práticas avaliativas presentes em contexto escolar estão em sintonia com as teorias sobre a avaliação e com o que versam os documentos educacionais sobre o referido tema. Não há um desconhecimento ou discordância das teorias sobre a avaliação; isso foi facilmente identificado quando realizamos a análise das concepções e práticas avaliativas em contexto escolar.

Apesar de a avaliação escolar ter como objeto a aprendizagem e a psicologia da educação ocupar-se das teorias da aprendizagem, observamos que esses conhecimentos não são considerados quando se discute a avaliação, daí o porquê de falarem mais alto as contribuições da didática sobre o modo de avaliar. Isto mostra uma lacuna nas teorizações sobre a avaliação, ou melhor, uma cisão entre os princípios teóricos da psicologia do desenvolvimento e aprendizagem e a didática. Parece não haver diálogo entre essas duas áreas do conhecimento no tema em questão.

Mas, se a avaliação escolar implica necessariamente em avaliar conhecimentos, conteúdos ensinados, objetivos propostos e alcançados, enfim, avaliar o que o aluno aprendeu; ou seja, se é uma atividade que permite acompanhar a aprendizagem do aluno, é necessário buscar em teorias que se ocupam da aprendizagem e do desenvolvimento cognitivo elementos que ajudem a compreender o que significa apreender algo. Pois, se não sabemos o que é aprender um 
conceito, ficamos sem critérios para avaliar a aprendizagem, e qualquer manifestação do aluno pode ser considerado um conceito aprendido.

Além disso, como afirma Sforni (2004, p. 185):

A ausência de critérios para a análise da aprendizagem dos alunos traz, conjuntamente, a ausência de critérios para a análise das ações docentes, o que acarreta o desenvolvimento de inúmeras tarefas sem valor formativo $[\ldots]$

Consideramos que a tarefa de avaliar não é fácil, pois ela vai além da escolha do instrumento a ser utilizado para a avaliação, se é a produção de um texto, uma cruzadinha ou a apresentação de um painel. Exige pensar em quais instrumentos são mais adequados para possibilitar que o aluno pense sobre o conceito estabelecendo relações com outros conceitos que fazem parte do sistema do qual é formado e também demonstre a capacidade de compreender os fenômenos que fazem parte da realidade objetiva, mediante os conceitos trabalhados.

Para isso é necessário buscar em teorias que se ocupam da aprendizagem e do desenvolvimento cognitivo elementos que ajudem a compreender o que significa apreender algo e, mais ainda, qual a especificidade da aprendizagem de conteúdos escolares, que funções psíquicas estão envolvidas nesse processo; ou seja, é necessário voltar-se para a relação do sujeito com o objeto de conhecimento, o que pode oferecer elementos para se pensar o que é a aprendizagem e, por decorrência, o "conteúdo" da avaliação, e não apenas a "forma" de avaliar.

\section{REFERÊNCIAS}

BRASIL. Parâmetros Curriculares Nacionais: Introdução. Brasília: MEC/ SEF, 1997.

BRASIL, Lei de Diretrizes e Bases da Educação Nacional. Lei n. 9394/96.

HOFFMAN, Jussara. Avaliação mediadora: uma prática em construção da pré-escola à universidade. Porto Alegre: Educação \& Realidade, 1993. 
HOFFMAN, Jussara. Avaliação: mito e desafio: uma perspectiva construtivista. 16.ed. Porto Alegre: Educação \& Realidade, 1995.

LEONTIEV, Aléxis. O desenvolvimento do psiquismo. Lisboa: Editora Livros Horizontes, 1978.

LEONTIEV, Aléxis. Os princípios do desenvolvimento mental e o problema do atraso mental. In: LURIA, A. R. et al. Psicologia e Pedagogia: bases psicológicas da aprendizagem e do desenvolvimento. Tradução: Rubens Eduardo Frias. São Paulo: Centauro, 2003.

LUCKESI, Cipriano Carlos. Avaliação da aprendizagem escolar. 7. ed. São Paulo: Cortez, 1998.

PERRENOUD, Philippe. Avaliação: da excelência à regulação das aprendizagens - entre duas lógicas. Porto Alegre: Artes Médicas, 1999.

SAUL, Ana Maria. Avaliação emancipatória: desafios à teoria e à prática de avaliação e reformação de currículo. 4.ed. São Paulo: Cortez: Autores Associados, 1988 .

SFORNI, Marta Sueli de Faria. Aprendizagem conceitual e organização do ensino: contribuições da teoria da atividade. Araraquara: Junqueira \& Marin, 2004.

SOUSA, Clarilza Prado de. Avaliação do rendimento escolar sedimentação de significados. In: SOUSA, Clarilza Prado de et al. Avaliação do rendimento escolar (Org.). 4. ed. Campinas: Papirus, 1995.

VIEIRA, Vanize A. M. de Andrade. Avaliação da aprendizagem conceitual: concepções, práticas e perspectivas. Dissertação (Mestrado em Educação) Universidade Estadual de Maringá, 2008.

VYGOTSKY, L.S. A construção do pensamento e da linguagem. Tradução: Paulo Bezerra. São Paulo: Martins Fontes, 2001.

Texto recebido em 26 de março de 2009.

Texto aprovado em 20 de setembro de 2009. 